\title{
Primary dural lymphoblastic B-cell lymphoma: a rare subtype of aggressive dural lymphoma
}

\author{
Christine Saraceni $^{1} \cdot$ Nicole Agostino $^{1} \cdot$ Shereen Gheith $^{2}$
}

Received: 5 June 2015 / Accepted: 30 July 2015 / Published online: 14 August 2015

(C) Springer-Verlag Berlin Heidelberg 2015

\begin{abstract}
Lymphomas arising in the dura mater represent a rare subset of primary central nervous system lymphoma (PCNSL). The majority of primary dural lymphoma (PDL) are low-grade marginal zone lymphomas (MZL) characterized by an indolent course and favorable long-term outcomes. Primary aggressive dural lymphomas are exceedingly rare with a paucity of cases reported in the literature. Herein, we describe a case of primary lymphoblastic dural lymphoma. To our knowledge, this is the second report of an isolated dural B-lymphoblastic lymphoma (B-LBL) in an immunocompetent patient.
\end{abstract}

Keywords B-lymphoblastic lymphoma $\cdot$ Primary CNS lymphoma $\cdot$ Dural lymphoma $\cdot$ Acute lymphoblastic lymphoma $\cdot$ B-ALL

\section{Introduction}

Primary dural lymphoma is a rare form of PCNSL, mostly described by case reports. The incidence of PDL is reported as $0.6-3 \%$ of all primary central nervous system lymphomas (incidence variable in studies) [1,2]. Aggressive NHL

Christine Saraceni

Christine.Saraceni@1vhn.org

1 Department of Hematology Oncology, Lehigh Valley Health Network, John and Dorothy Morgan Cancer Center, 1240 S. Cedar Crest Blvd, Suite 401, Allentown, PA 18103, USA

2 Department of Pathology, Lehigh Valley Health Network, Allentown, PA 18103, USA dural subtypes are unique as most aggressive lymphomas of the meninges are associated with brain parenchymal or systemic involvement. The majority of PDL are low-grade, B-cell marginal zone lymphoma (MZL) with rare cases of low-grade follicular subtypes reported [1]. Aggressive dural lymphomas including diffuse large B-cell lymphoma (DLBCL) and lymphoblastic subtypes are limited to case reports and small case series [1, 3-6] (Table 1). PDL have favorable outcomes and the indolent forms are biologically distinct from parenchymal PCNSL or systemic lymphoma metastatic to the CNS [1]. Whether B-lymphoblastic subtypes will follow this favorable trajectory remains unclear. The paucity of dural lymphoblastic lymphoma cases in the literature make standardized treatment and prognostication difficult.

\section{Case history}

A 42-year-old immunocompetent male presented with several weeks of a left frontal headache, lack of coordination, and tendency to drift to the left while driving. Magnetic resonance imaging (MRI) revealed a large enhancing extra-axial mass along the right posterior superior parietal convexity invading the calvarium (Fig. 1a). A second 18-mm focus of enhancement was also noted within the left parietal calvarium distinct from the tumor bulk (Fig. 1b). The tumor was protruding from the outer table of the calvarium and in areas, invaded the meninges and infiltrated into the subdural space. Excision of the tumor was performed and submitted for pathology. A diagnosis of B-LBL was rendered. Complete blood count was only notable for a mild thrombocytosis: platelet count $454,000 / \mu \mathrm{L}$ which was present since 


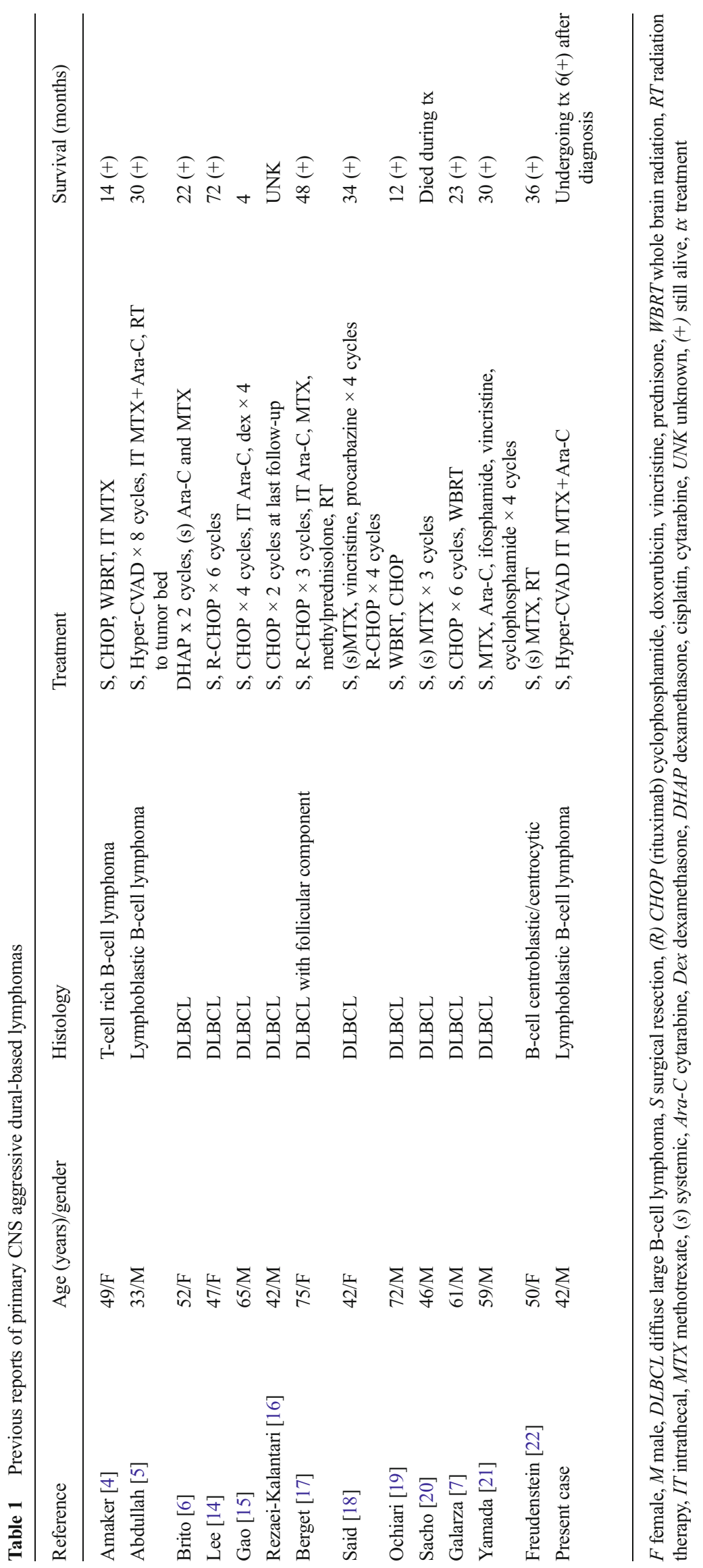



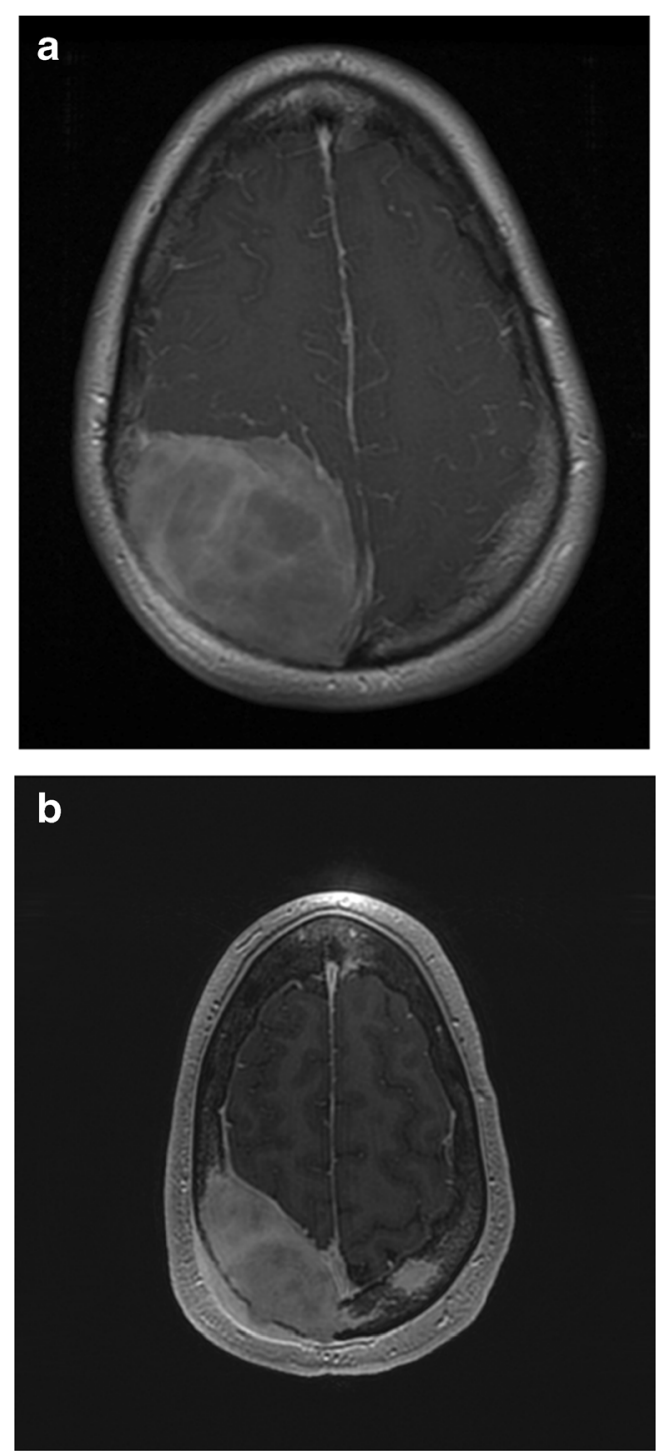

Fig. 1 MRI (T1 axial flare, post-contrast). a Large extra-axial enhancing mass along the right parietal convexity measuring $8.7 \times 5.9 \times 6.6 \mathrm{~cm}$. b Separate abnormal foci of enhancement within the left calvarium distinct from the larger mass

2007. His thrombocytosis fluctuated in the range of $450,000-650,000 / \mu \mathrm{L}$. Computed tomography (CT) of the chest, abdomen, and pelvis and positron emission tomography (PET) revealed no abnormalities. Cerebrospinal fluid examination was unremarkable.

The patient was treated with hyper-CVAD (fractionated cyclophosphamide, vincristine, doxorubicin, and dexamethasone) alternating with high-dose cytarabine and methotrexate in conjunction with prophylactic intrathecal methotrexate and cytarabine. Six months since diagnosis, he has tolerated 7 cycles of treatment without complication and will receive consolidative radiation therapy at systemic therapy completion. MRI of the brain after 5 months showed no evidence of recurrence.

\section{Results}

Tumor resection pathology Touch imprint from the brain tumor biopsy revealed numerous small to medium-sized lymphoid cells with scant cytoplasm, irregular nuclei with open vesicular chromatin, and occasional prominent nucleoli resembling blasts (Fig. 2a). Hematoxylin and eosin (H\&E) stain showed sheets of numerous small/medium lymphoid cells with frequent apoptotic bodies and occasional mitosis (Fig. 2b). Immunohistochemistry (IHC) was performed on deparaffinized, formalin-fixed brain tissue and showed the lymphoma cells to be diffusely positive for CD45, BCL-2, CD79a, PAX5, CD 10, and TDT and negative for CD20, CD3, CD5, BCL-6, BCL-1, and EBER (EBV by in situ hybridization) (Fig. 2c). Ki-67 showed high proliferation index. Fluorescence in situ hybridization (FISH) analysis on paraffin-embedded sections of brain tissue showed copy gain of BCL-2 (81\% cells) and MALT1 (77\% cells) with loss of CEP9 (65\% cells) and ETV6 (68\% cells). No BCL-6, $C C N D 1 / I G H$, or $M Y C / I G H$ rearrangements were found.

Bone marrow biopsy Bone marrow biopsy revealed trilineage hematopoiesis and slight megakaryocytic hyperplasia without morphologic or immunophenotypic evidence of a hematolymphoid neoplasm. Bone marrow molecular studies performed by polymerase chain reaction (PCR) were negative for JAK2 V617F, calreticulin and MPL codon 505 and 515 gene mutations, cytogenetics showed 46, XY [7], myeloproliferative disorder FISH panel showed normal signal patterns for $C H I C 2$, PDGFRB, FGFR1, and BCR/ABL.

Peripheral blood Molecular studies by PCR were negative for $J A K 2$ exon 12 mutation.

\section{Discussion}

Primary dural-based lymphoblastic lymphoma are sparsely reported in the literature. The pathogenesis of PDL is poorly understood as the dura is devoid of lymphoid tissue. Postulated mechanisms, although this has not been definitively proven, include the action of an antigen-independent environmental stimulus or an autoimmune mechanism that could initiate an inflammatory response with subsequent selection of a clonal lymphoid population $[1,8]$.

The optimal induction therapy for adult B-LBL has not been fully delineated. The most commonly used induction regimes are derived from pediatric protocols and include intensive chemotherapy with CNS prophylaxis followed by prolonged maintenance therapy. ALL (acute lymphoblastic leukemia)-specific chemotherapy regimens have been favored over lymphoma-specific regimens for high risk patients with LBL [9-11]. 
Fig. 2 a Touch imprint showing multiple lymphoblasts with smallto medium-sized cells, scant cytoplasm and open vesicular chromatin (original magnification $\times 1000$ ). b Hematoxylin and eosin stains showing sheets of small lymphoid cells with frequent apoptotic bodies and occasional mitosis (original magnification $\times 500$ ). $\mathbf{c}$ The tumor cells are diffusely reactive for $\mathrm{CD} 79 \mathrm{a}$, PAX5, and TDT and negative for CD20 (original magnification $\times 200)$ a

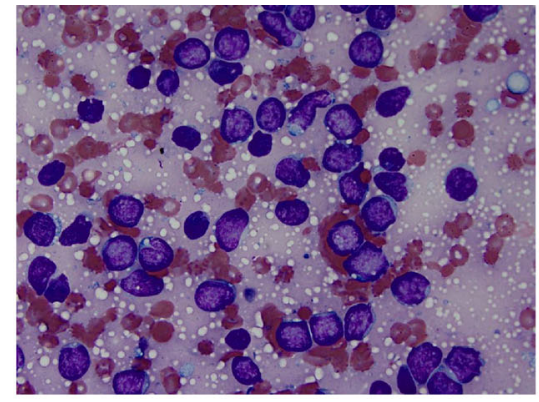

C
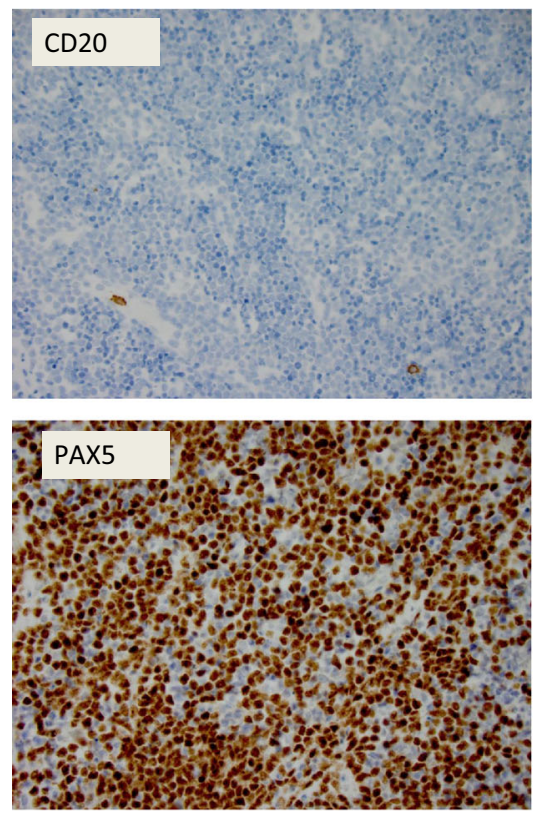

b
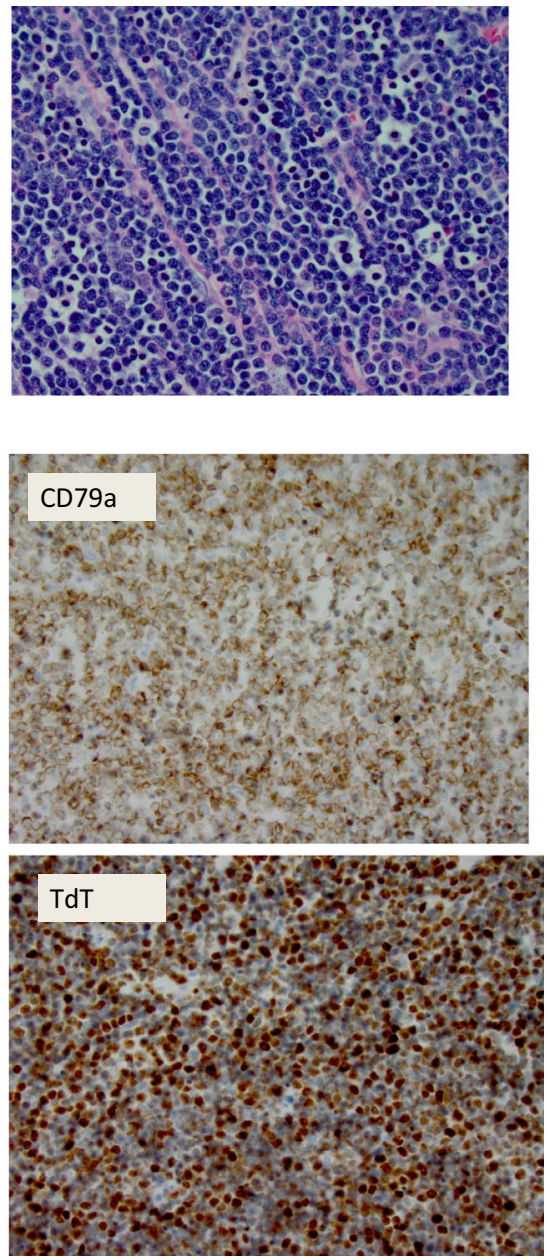

In our case, complete resection of the tumor was performed followed by treatment with an ALL protocol using hyperCVAD chemotherapy and intrathecal CNS prophylaxis with each course. He also underwent surveillance with bone marrow biopsy after four courses of treatment which remained negative. The role of consolidative radiation therapy in our particular case is less well defined. Prior reports of patients with B-LBL of various sites reveal high rates of complete remission and overall survival [12]. The prognosis of dural DLBCL based on limited case reports, appears favorable [6]. An interesting aspect of our case was the patient's history of thrombocytosis and findings of slight megakaryocytic hyperplasia on bone marrow biopsy. This raised initial concern for an underlying myeloproliferative disorder (MPD). Concurrence of B-lymphoblastic leukemia and myeloproliferative neoplasm harboring a MPL W515S mutation has been previously reported [13]. However, the $M P L$ mutation was not detected in our patient.

To our knowledge, this is the second reported case of BLBL with isolated dural involvement in the absence of other systemic sites of disease. The majority of B-LBL present systemically with concomitant bone marrow involvement and/or leukemic component. As we gain further insight into the natural history and pathogenesis of primary (aggressive) dural lymphoma, our understanding of its behavior will broaden and improve our therapeutic approach.

\section{Compliance with ethical standards}

Ethical approval All procedures performed were in accordance with the ethical standards of the institutional guidelines and with the 1964 Helsinki declaration and its later amendments or comparable ethical standards.

Informed consent Informed consent was obtained from the patient included in this case report.

Conflict of interest Christine Saraceni declares no conflicts of interest. Nicole Agostino declares no conflicts of interest, and Shereen Gheith declares no conflicts of interest. 


\section{References}

1. Iwamoto FM, Abrey LE (2006) Primary dural lymphomas: a review. Neurosurg Focus 21(5):E5

2. Zimmerman HM (1975) Malignant lymphomas of the nervous system. Acta Neuro Pathol Suppl 6:69-74

3. Clark AJ, Lee K, Broaddus WC, Martin MJ, Ghatak NR, Grossman CE, Baker S Jr, Baykal A (2010) Primary brain T-cell lymphoma of the lymphoblastic type presenting as altered mental status. Acta Neurochir 152:163-168

4. Amaker BH, Chatak NR, Jebraili SA, Ferreira-Gonzalez A, Kornstein MJ (2000) Primary T-cell rich B-cell lymphoma masquerading as a meningioma. Arch Pathol Lab Med 124:17001703

5. Abdullah S, Morgensztern D, Rosado MF, Lossos IS (2005) Primary lymphoblastic B-cell lymphoma of the cranial dura mater, a case report and review of the literature. Leukemia \& Lymphoma 46(11):1651-1657

6. Brito AB, Reis F, de Souza CA, Vassallo J, Lima CS (2014) Intracranial primary dural diffuse large B-cell lymphoma successfully treated with chemotherapy. Int J Clin Exp Med 7(2):456-460

7. Galarza M, Gazzeri R, Elfeky HA, Johnson RR 2nd (2006) Primary diffuse large B-cell lymphoma of the dura mater and cranial vault. Case report and literature review. Neurosurg Focus 21(5):E10, Review

8. McCann KJ, Ashton-Key M, Smith K, Stevenson FK, Ottensmeier CH (2009) Primary central nervous system lymphoma: tumorrelated clones exist in the blood and bone marrow with evidence for separate development. Blood 113(19):4677-4680

9. Coleman CN, Picozzi VJ, Cox RS, McWhirter K, Weiss LM, Cohen JR, Yu KP, Rosenberg SA. (1896) Treatment of lymphoblastic lymphoma in adults. JCO 4:1628-1637

10. Thomas DA, O'Brien S, Cortes J, Giles FJ, Faderi S, Verstovsek S, Ferrajoli A, Koller C, Beran M, Pierce S, Ha CS, Cabanillas F, Keating MJ, Kantarjian H (2004) Outcome with hyper-CVAD regimens in lymphoblastic lymphoma. Blood 104(6):1624-1630

11. Shi Y, Zhou S, He X, Han X, Wu S, Pan F, Liu P, Liu Y, Lei Y, Zhang H, Yang J, Qin Y, Zhang C, Yang S, Zhao L, Luo K, Wu G, Sun Y, Shi Y (2015) Autologous hematopoietic stem cell transplantation in chemotherapy-sensitive lymphoblastic lympho$\mathrm{ma}$, treatment outcome and prognostic factor analysis. Chin $\mathrm{J}$ Cancer Res 27(1):66-73

12. Maitra A, McKenna RW, Weinberg AG, Schneider NR, Kroft SH (2001) Precursor B-cell lymphoblastic lymphoma. Am J Clin Pathol 115:868-875

13. Tao J, Zhang X, Lancet J, Bennett JM, Cai L, Papenhausen P, Moscinski L, Zhang L (2014) Concurrence of B-lymphoblastic leukemia and myeloproliferative neoplasm with copy neutral loss of heterozygosity at chromosome $1 \mathrm{p}$ harboring a MPL W515S mutation. Cancer Genet 207(10-12):489-494

14. Lee WH, Kim B, Kim MS (2014) A case of primary dural lymphoma: diffuse large B-cell type. Turk Neurosurg 24(5):799-803

15. Gao Y, Zhong C, Jiang J (2014) Primary diffuse large B-cell lymphoma of the dura mimicking a meningioma with intervening skull bone invasion. J Neurooncol 120(1):215-217

16. Rezaei-Kalantari K, Samimi K, Jafari M, Karimi MA, Ansari K, Davoodi M, Nabi-Meybodi M, Gorkian M (2012) Primary diffuse large B cell lymphoma of the cranial vault. Iran J Radiol 9(2):88-92

17. Berget E, Helgeland L, Lehmann AK, Smievoll AI, Vintermyr OK, Mork SJ (2013) Acta. Oncol 52(5):1047-1049

18. Said R, Rizk S, Dai Q. Clinical challenges of primary diffuse large B-cell lymphoma of the dura: case report and literature review (2011) ISRN Hematol 2011; 945212. doi: 10.5402/2011/945212. Epub 2011 Apr 27

19. Ochiari H, Kawano H, Miyaoka R, Kawano N, Shimao Y, Kawasaki K (2010) Primary diffuse large B-cell lymphomas of the temporoparietal dura mater and scalp without intervening skull bone invasion. Neurol Med Chir 50(7):595-598

20. Sacho RH, Kogels M, du Plessis D, Jowitt S, Josan VA (2010) Primary diffuse large B-cell central nervous system lymphoma presenting as an acute space-occupying subdural mass. J Neurosurg 113(2):384-387

21. Yamada SM, Ikawa N, Toyonaga S, Nakabayashi H, Chang-Park K, Shimizu K(2006) Primary malignant B-cell type dural lymphoma: case report. Surg Neurol 66(5):539-543

22. Freudenstein D, Bornemann A, Ernemann U, Boldt R, Duffner F (2000) Intracranial malignant B-cell lymphoma of the dura. Clin Neuropathol 19(1):34-37 